\title{
Simplified Model for the Hybrid Method to Design Stabilising Piles Placed at the Toe of Slopes
}

\author{
Dib M. ${ }^{1}$ and Kouloughli S. ${ }^{1}$ \\ ${ }^{1}$ Université des frères Mentouri, Civil Engineering department, Constantine, Algeria
}

\begin{abstract}
Stabilizing precarious slopes by installing piles has become a widespread technique for landslides prevention. The design of slope-stabilizing piles by the finite element method is more accurate comparing to the conventional methods. This accuracy is because of the ability of this method to simulate complex configurations, and to analyze the soil-pile interaction effect. However, engineers prefer to use the simplified analytical techniques to design slope stabilizing piles, this is due to the high computational resources required by the finite element method. Aiming to combine the accuracy of the finite element method with simplicity of the analytical approaches, a hybrid methodology to design slope stabilizing piles was proposed in 2012. It consists of two steps; (1): an analytical estimation of the resisting force needed to stabilize the precarious slope, and (2): a numerical analysis to define the adequate pile configuration that offers the required resisting force. The hybrid method is applicable only for the analysis and the design of stabilizing piles placed in the middle of the slope, however, in certain cases like road constructions, piles are needed to be placed at the toe of the slope. Therefore, in this paper a simplified model for the hybrid method is dimensioned to analyze and design stabilizing piles placed at the toe of a precarious slope. The validation of the simplified model is presented by a comparative analysis with the full coupled finite element model.
\end{abstract}

\section{Introduction}

Nailing unstable slopes using piles is one of the successful reinforcement techniques. Piles were proven to be efficient to stabilize precarious slopes through the additional resisting force that they offer. Many authors studied this subject, among them: De Beer and Walleys (1972), Ito and Matsui (1975), Sommer (1977), Fukuoka (1977), Wang et al. (1979), Nethero (1982), Oakland and Chameau (1984), Poulos (1995), and Poulos and Chen (1997).

In general, the Design methods for slope stabilizing piles are: pressure or displacement-based method, and numerical methods. In 2012, Kourkoulis et al. proposed a hybrid method for the design of slope-stabilizing piles. This method merges the accuracy of the finite element method with simplicity of the analytical approaches. However, the hybrid method was only developed to analyze piles placed in the middle of unstable slopes.

\section{The hybrid method for analysis and design of slope stabilizing piles}

The hybrid method for the design of slope-stabilizing piles was proposed by Kourkoulis et al. in 2012. It consists of two steps; (1): an analytical estimation of the resisting force needed to stabilize the precarious slope, and (2): a numerical analysis to define the adequate pile configuration that offers the required resisting force for a desired pile head displacement.

In the analytical part, the estimations of the needed resisting force to stabilize the precarious slope is done by the conventional slope stability techniques. However, in the numerical part, Kourkoulis et al. proposed a new approach. This approach aims to reduce the numerical cost by reducing the size of the model; so instead of modeling the entire slope-piles system, only two piles and the surrounded soil are modeled as presented in figure 1. 


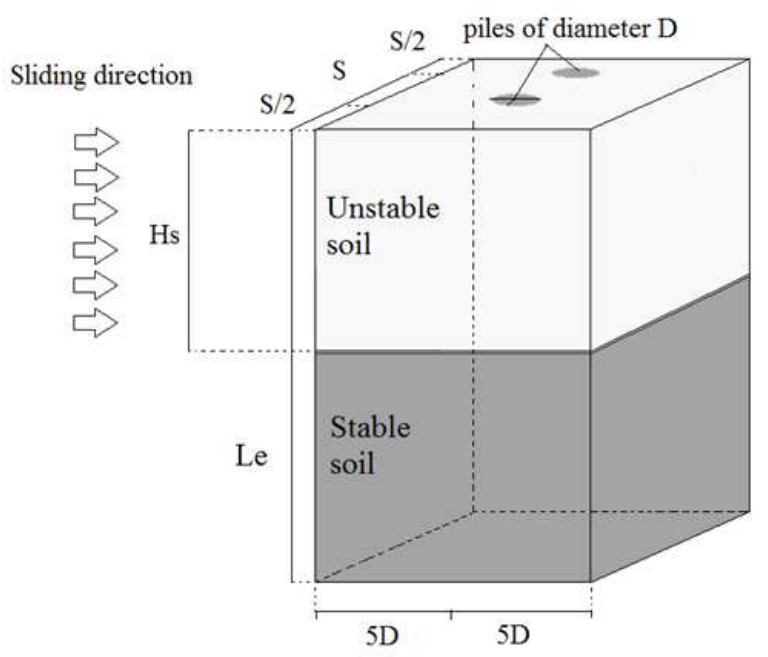

Fig. 1. The simplified model for the hybrid method [12].

The length of the simplified model is $10 \mathrm{D}$, and its width is $2 \mathrm{~S}$ (two times the spacing between piles). In full scale, it is assumed that the slope is reinforced by a row of piles with spacing $S$ repeated indefinitely. Hs is the sliding depth, and Le represents the pile length.

For piles placed in the middle of precarious slopes, it was found that beyond a distance of 5D up-slope of the piles row, the soil displacement profile becomes almost uniform [12]. Therefore, 10D (2 times 5D) was chosen to be the length of the simplified model.

The Hybrid method was developed to design piles placed in the middle of the slope, but in certain cases like road constructions, piles are needed to be placed at the toe of the slope. Therefore, in this paper a simplified model for the hybrid method is dimensioned to analyse and design stabilizing piles placed at the toe of a precarious slope.

\section{Investigation of the uniformity of soil displacement profile for piles placed at the toe of the slope}

\subsection{Properties of slopes and piles}

In order to investigate the uniformity of soil displacement profile for piles placed at the toe of the slope, different slope geometries with pre-existing potential sliding interface (PEPSI) were tested, with inclination angle ranging from $21^{\circ}$ to $26^{\circ}$ and pile spacing of $3 \mathrm{D}$ and $4 \mathrm{D}$.

For the unstable and the stable parts of the slopes, soil properties are resumed in table 1 . Soil is simulated with an elastoplastic model (Mohr-Coulomb failure criterion).
Table 1. Soil properties.

\begin{tabular}{|c|c|c|c|}
\hline & $\begin{array}{c}\text { Unit Wight } \\
\left(\mathrm{KN} / \mathrm{m}^{3}\right)\end{array}$ & $\begin{array}{c}\text { Undrained } \\
\text { shear } \\
\text { strength } \mathrm{Cu} \\
(\mathrm{KPa})\end{array}$ & $\begin{array}{c}\text { Young } \\
\text { modulus E } \\
(\mathrm{KPa})\end{array}$ \\
\hline $\begin{array}{c}\text { Unstable } \\
\text { part }\end{array}$ & 16 & 72 & 48000 \\
\hline Stable part & 19.2 & 191 & 482000 \\
\hline
\end{tabular}

Concrete piles with $1.2 \mathrm{~m}$ diameter were used in the analysis, where an elastic behaviour was chosen in the simulations. Materials properties of piles are resumed in table 2.

Table 2. Piles properties.

\begin{tabular}{|c|c|c|c|}
\hline & $\begin{array}{c}\text { Unit Wight } \\
\left(\mathrm{KN} / \mathrm{m}^{3}\right)\end{array}$ & $\begin{array}{c}\text { Young } \\
\text { modulus E } \\
(\mathrm{KPa})\end{array}$ & $\begin{array}{c}\text { Poisson's } \\
\text { ratio }\end{array}$ \\
\hline Concrete & 25 & 25000000 & 0.2 \\
\hline
\end{tabular}

\subsection{The numerical analysis}

Fully coupled slopes with pre-existing potential sliding interface (PEPSI) were analyzed using finite element code Abaqus, an example is presented in figure 2.

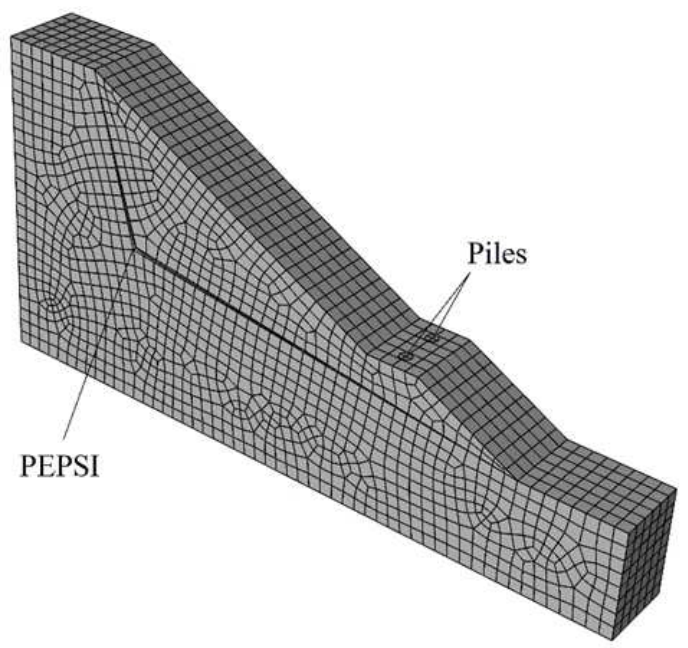

Fig. 2. Finite element mesh of the fully coupled slope reinforced by two piles with preexisting potential sliding interface (PEPSI).

\subsection{Results and discussions}

By analysing the displacement profiles, the following results were obtained: Figure 3 represents the displacement profiles at a distance of 5D up-slope of the piles. 


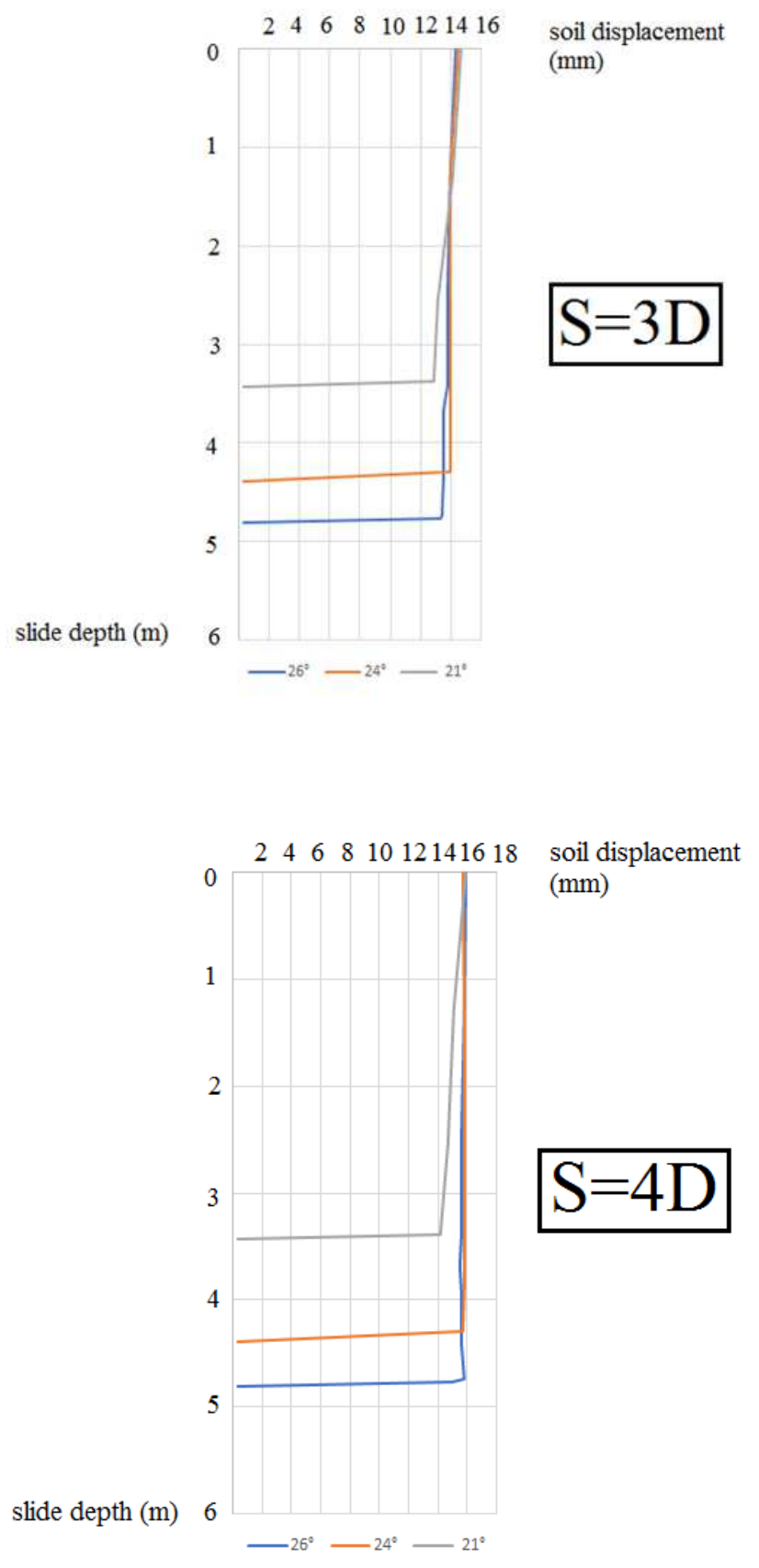

Fig.3. Soil displacement profiles at a distance of 5D up-slope of the piles row for different slopes inclinations, and pile spacings of 3D and 4D.

One can notice that either for pile spacing of $3 \mathrm{D}$ or 4D, the soil displacement profile at a distance of 5D upslope of the piles is almost uniform. Figure 4 represents a cut at a distance of 5D upslope of piles with soil displacement contours.

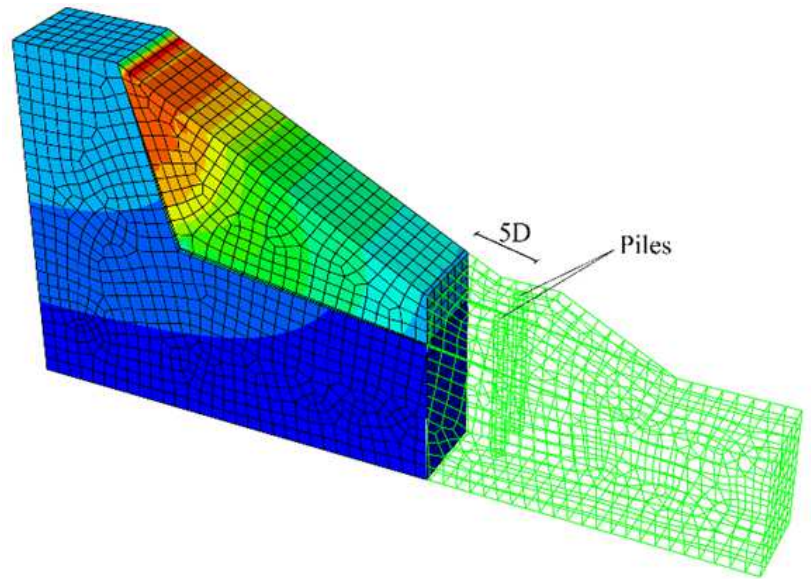

Fig. 4. Cut at a distance of 5D up-slope of piles with soil displacement contours.

\section{The simplified model for the hybrid method to design stabilizing piles placed at the toe of slopes}

As found above, the soil displacement profile at a distance of $5 \mathrm{D}$ up-slope the row of piles is almost uniform. Therefore, the simplified model for the hybrid method to design stabilizing piles placed at the toe of slopes is identical to that developed by Kourkoulis et al. in 2012, The length of simplified model is $10 \mathrm{D}$, and its width is $2 \mathrm{~S}$, as shown in figure 1 .

\section{Validation of the simplified model against fully coupled reinforced slope analysis}

In order to validate the simplified model, a fully coupled analysis was conducted first, it consists of a slope with $24^{\circ}$ inclination reinforced by a row of concrete piles of $1.2 \mathrm{~m}$ diameter, and spacing $\mathrm{S}=3 \mathrm{D}$. Then a simplified model was analysed as presented in figure 5 . 


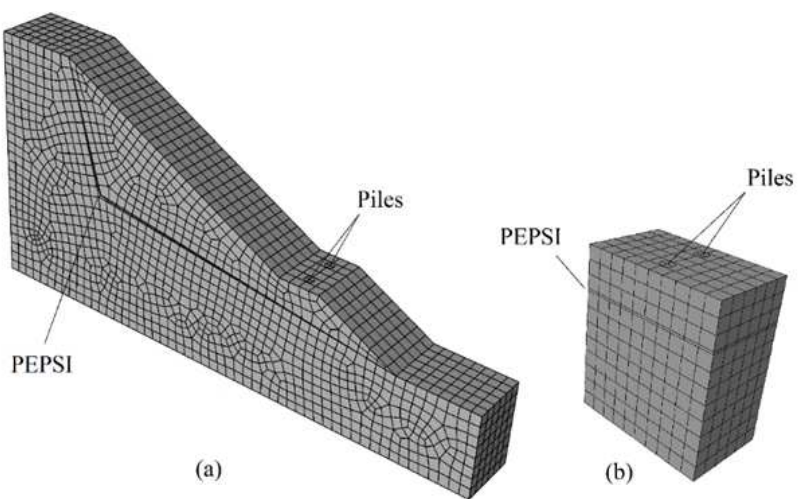

Fig. 5. The validation of the simplified model, finite element mesh for: (a) the fully coupled model, (b) the simplified model.

\section{Results and discussions}

For the fully coupled model, the pile head deflection necessary to stabilize the slope by coupled methodology was found to be $6.3 \mathrm{~mm}$.

Using the method of slices, it was found that the required resisting force (RF) needed to stabilize the slope is $341 \mathrm{KN} / \mathrm{m}$. After the analysis of the simplified model, the needed RF $(341 \mathrm{KN} / \mathrm{m})$ was given by the piles at a pile head deflection of $7.4 \mathrm{~mm}$, with an error of $17 \%$. (figure 6)

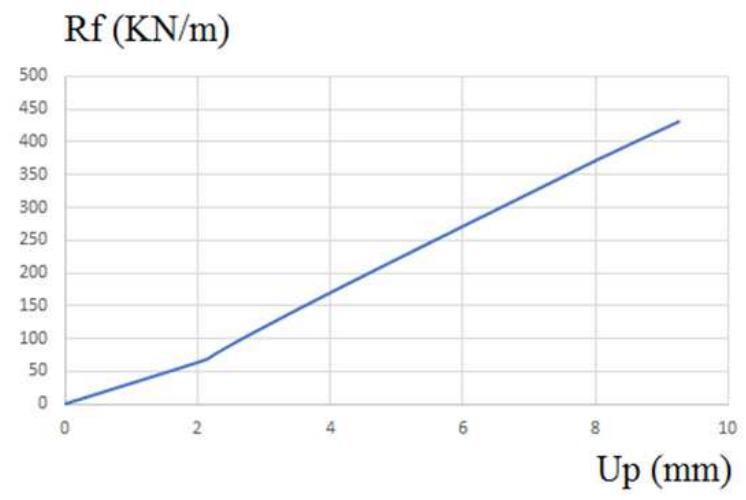

Fig. 6. Resisting force (Rf) with respect to pile head deflection (Up) given by the simplified model.

\section{Conclusions}

In this research about the simplified model for the hybrid method to design stabilizing piles placed at the toe of slopes, the following conclusions were reached:

The displacement profile at a distance of 5D up-slope the pile location may be considered as uniform.
The simplified model for the analysis and the design of slope stabilizing piles placed at the toe of the slope is identical to that of piles located in the middle of the slope.

\section{References}

1. De Beer, E. E. and Wallays, M., Forces Induced in Piles by Unsymmetrical Surcharges on the Soil Around the Pile, International Proceedings of the 5th Euro Conference on Soil Mechanics and Foundation Engineering, Madrid, 1, 154176 (1972)

2. Ito, T. and Matsui, T., Methods To Estimate Lateral Force Acting on Stabilizing Piles, Soils and Foundations, 15, 4, 43-59 (1975)

3. Sommer, H., Creeping slope in a stiff clay, Proc., 9th Int. Conf. on Soil Mechanics and Foundation Engineering, A. A. Balkema, Rotterdam, Netherlands, 113-118 (1977)

4. Fukuoka, M., The effects of horizontal loads on piles due to landslides, Proc., 9th Int. Conf. on Soil Mechanics and Foundation Engineering, Japanese Society of Soil Mechanics and Foundation Engineering, Tokyo, 27-42 (1977)

5. Wang, M. C., Wu, A. H., and Scheessele, D. J., Stress and deformation in single piles due to lateral movement of surrounding soils, Behavior of deep foundations: ASTM special technical publication, 670, Raymond Lunggren, ed., ASTM, West Conshohocken, PA, 578-591 (1979)

6. Nethero, M. F., Slide control by drilled pier walls, Application of Walls to Landslide Control Problems, Proc., ASCE National Convention, $R$. B. Reeves, ed., ASCE, New York, 19-29 (1982)

7. Oakland, M. W. and Chameau, J. L. A., FiniteElement Analysis of Drilled Piers Used for Slope Stabilization: In Laterally Loaded Deep Foundations: Analysis and Performance, ASTM STP 835, J.A. Langer, E.T. Mosley and C.D. Thompson, Eds., ASTM, 182-193 (1984)

8. Poulos, H. G., Design of Reinforcing Piles to Increase Slope Stability, Canadian Geotechnical Journal, 32, 808-818 (1995)

9. Poulos H. G. and Chen L. T., Pile Response Due to Excavation-Induced Lateral Soil Movement, Journal of Geotechnical and Geoenvironmental Engineering, 123, 2, 94-99 (1997) 
10. Kourkoulis, R. Interplay of Mat Foundations and Piles With a Failing Slope. PhD thesis, National Technical University of Athens, Greece (2009)

11. Kourkoulis, R. Gelagoti, F. Anastasopoulos, I. and Gazetas, G., Slope Stabilizing Piles and Pile-Groups: Parametric Study and Design Insights, Journal of Geotechnical and Geoenvironmental Engineering, 137, 7, 663-678 (2011)

12. Kourkoulis, R. Gelagoti, F. Anastasopoulos, I. and Gazetas, G., Hybrid Method for Analysis and Design of Slope Stabilizing Piles, Journal of Geotechnical and Geoenvironmental Engineering, 138, 1, 1-14 (2012)

13. Gazetas, G., and Uddin, N., Permanent deformation of preexisting sliding surfaces in dams, J. Geotech. Eng., 120, 11, 2041-2061 (1994) 